\title{
PENGAMBILAN KEPUTUSAN BERBASIS KOMPUTER DENGAN METODE SIMPLE MULTI ATTRIBUTE RATING TECHNIQUE DALAM MENENTUKAN DOSEN PEMBIMBING
}

\author{
Harold Situmorang ${ }^{1}$, Rianto Sitanggang ${ }^{2}$, Burhanuddin Damanik ${ }^{3}$, Immanuel H Manurung ${ }^{4}$ \\ 1,2,3,4 Universitas Sari Mutiara Indonesia \\ 1,2,3,4Jl. Kapten Muslim No. 79 Medan \\ Iharoldsitumorang.hs@gmail.com, ${ }^{2}$ rianto.sitanggang79@gmail.com, ${ }^{3}$ damanikus@yahoo.com, ${ }^{4}$ nuelgunawan@gmail.com
}

Abstrak-Penentuan dosen pembimbing skripsi di Universitas Sari Mutiara Indonesia secara khusus program studi Sistem Informasi ditangani oleh ketua program studi, dimana dalam prosesnya dilakukan dengan menentukan secara langsung dengan menyesuaikan pendidikan, kompetensi dan fungsional yang dimiliki calon dosen pembimbing tanpa mempertimbangkan kriteria lainnya seperti: jumlah bimbingan, jadwal bimbingan, durasi bimbingan dan layanan bimbingan. Selain itu, dikarenakan banyaknya mahasiswa yang mengajukan dosen pembimbing, ketua program studi membutuhkan waktu yang cukup banyak dalam menentukan kriteria yang cocok untuk masing-masing judul. Berdasarkan paparan diatas, maka dalam penelitian ini dibuat sistem dengan teknik pengambilan keputusan menggunakan metode Simple Multi Attribute Rating Technique (SMART) dengan tujuan memberikan rekomendasi dosen pembimbing bagi setiap judul yang diajukan. Dari hasil pengujian yang dilakukan, sistem mampu memberikan rekomendasi dosen pembimbing kepada pengguna berdasarkan perhitungan yang dilakukan menggunakan metode SMART.

Kata Kunci-SPK, SMART, Dosen Pembimbing, Skripsi.

Abstract-Determination of thesis supervisors at Sari Mutiara University, Indonesia, special study program Information System approval by the head of the studio program, which in the process is carried out by determining directly by adjusting education, competencies and functions intended for prospective supervisors, guidance, duration of guidance and guidance services. In addition, regarding the number of students who apply for appointment, the head of the study program requires sufficient time to determine the appropriate choice for each title. Based on the above assessment, in this study the system was made with a decision making technique using the Simple Multi Attribute Rating Technique (SMART) method with the aim of giving a supervisor's recommendation for each proposed title. From the results of tests carried out, the system can provide guidance to the user who uses calculations performed using the SMART method.

Keywords - SPK, SMART, Supervisor, Thesis.

\section{PENDAHULUAN}

Berkembangnya teknologi informasi secara khusus teknologi komputer dapat digunakan dalam menyelesaikan permasalahan dalam berbagai bidang. Teknologi komputer yang cukup berkembang pesat saat ini yaitu pemanfaatan teknologi komputer dalam pengambilan keputusan (decision support system). Pengambilan Keputusan adalah salah satu kegiatan yang paling mendasar dalam kehidupan sehari-hari. Dalam proses pengambilan keputusan seringkali dihadapkan pada banyak alternatif yang dapat dipilih, sehingga untuk suatu permasalahan beberapa pembuat keputusan dapat mengambil keputusan yang berbeda.

Dalam dunia pendidikan, pemanfaatan teknik pengambilan keputusan dapat ditemukan pada saat pennetuan dosen pembimbing skripsi dimana dalam prosesnya memerlukan penyesuaian kriteria-kriteria yang sesuai dengan judul yang diajukan. Kondisi saat ini di Universitas Sari Mutiara Indomesia secara khusus program studi Sistem Informasi, penentuan dilakukan secara langsung oleh ketua program studi dengan mempertimbangkan kompetensi, fungsional dan pendidikan dari calon dosen pembimbing dengan mengesampingkan beberapa kriteria lain yang dapat meningkatkan hasil bimbingan seperti: jumlah, jadwal, durasi dan layanan bimbingan skripsi calon dosen pembimbing skripsi. Oleh karena itu, dibutuhkan suatu sistem pendukung keputusan yang berguna untuk menentukan dosen pembimbing skripsi dan skripsi yang diajukan mahasiswa seuai dengan kompetensi dan banyaknya jumlah bimbingan dapat dibatasi bagi setiap dosen pembimbing. Selain itu, dikarenakan banyaknya mahasiswa yang mengajukan dosen pembimbing, maka dibutuhkan waktu yang lama untuk menyelesaikannya.

Penelitian ini akan memanfaatkan teknik pengambilan keputusan berbasis komputer dalam 
menentukan dosen pembimbing dengan mempertimbangkan beberapa kriteria yaitu: pendidikan, jabatan fungsional, kompetensi, jumlah bimbingan, jadwal bimbingan, durasi bimbingan dan layanan bimbingan. Dalam proses penentuan akan Page|211 menggunakan metode SMART (Simple Multi Attribute Rating Technique). Metode SMART merupakan suatu metode pengambilan keputusan multi kriteria yang didasarkan pada teori bahwa setiap alternatif terdiri dari sejumlah kriteria yang memiliki nilai dan setiap kriteria memiliki bobot untuk menggambarkan seberapa penting nilainya dibandingkan dengan kriteria yang lain. Metode SMART lebih sering digunakan karena kesederhanaannya dalam merespon kebutuhan pembuat keputusan dan menganalisa respon.

Dengan adanya sistem pendukung keputusan penentuan dosen pembimbing skripsi diharapkan proses penentuan dosen pembimbing skripsi dapat dilakukan dengan mudah dan dapat membantu pihak institusi secara khusus program studi untuk menentukan dosen pembimbing skripsi.

\section{KAJIAN TEORI}

\section{A. Metode SMART (Simple Multi Attribute Rating Technique)}

SMART merupakan metode pengambilan keputusan yang multiatribut. Teknik pembuatan keputusan multiatribut ini digunakan untuk membantu stakeholder dalam memilih antara beberapa alternatif. Setiap alternatif terdiri dari sekumpulan atribut dan setiap atribut mempunyai nilai-nilai, nilai ini diratarata dengan skala tertentu. Setiap atribut mempunyai bobot yang menggambarkan seberapa penting dibandingkan dengan atribut lain.

Dengan SMART pembobotan atribut dilakukan dengan dua langkah yaitu:

1. Mengurutkan kepentingan suatu atribut dari level terburuk ke level terbaik.

2. Membuat perbandingan rasio kepentingan setiap atribut dengan atribut lain dibawahnya.

SMART lebih banyak digunakan karena kesederhanaanya dalam merespon kebutuhan pembuat keputusan dan caranya menganalisa respon. Analisa yang terlibat adalah transparan sehingga metode ini memberikan pemahaman masalah yang tinggi dan dapat diterima oleh pembuat keputusan. Pembobotan pada SMART menggunakan skala antara 0 sampai 1 , sehingga mempermudah perhitungan dan perbandingan nilai pada masing-masing alternatif. Pemilihan keputusan adalah mengidentifikasi mana dari $\mathrm{n}$ alternatif yang mempunyai nilai fungsi terbesar. Teknik SMART:

1. Langkah 1: menentukan jumlah kriteria

2. Langkah 2: sistem secara default memberikan skala 0-100 berdasarkan prioritas yang telah diinputkan kemudian dilakukan normalisasi.

$$
\text { Normalisasi }=\frac{w_{j}}{\sum w_{j}}
$$

Keterangan :

$$
\begin{aligned}
& w_{j} \quad \text { : bobot suatu kriteria } \\
& \sum w_{j}: \text { total bobot semua kriteria }
\end{aligned}
$$

3. Langkah 3: memberikan nilai kriteria untuk setiap alternatif.

4. Langkah 4: hitung nilai utility untuk setiap kriteria masing-masing.

$$
u_{i}\left(a_{i}\right)=100 \frac{\left(C_{\max }-C_{\text {out }}\right)}{\left(C_{\max }-C_{\text {min }}\right)} \%
$$

Keterangan :

$$
\begin{aligned}
& u_{i}\left(a_{i}\right): \text { nilai utility kriteria ke-1 untuk } \\
& \text { kriteria ke-i } \\
& C_{\max }: \text { nilai kriteria maksimal } \\
& C_{\min }: \text { nilai kriteria minimal } \\
& C_{\text {out } i}: \text { nilai kriteria ke-i }
\end{aligned}
$$

5. Langkah 5: hitung nilai akhir masing-masing.

$$
u\left(a_{i}\right)=\sum_{J=1}^{m} w_{j} u_{i}\left(a_{i}\right),
$$

\section{B. Skripsi, Pembimbing dan Penguji}

Skripsi merupakan suatu karya ilmiah yang disusun mahasiswa untuk menyelesaikan studinya melalui proses berpikir ilmiah, kreatif, integratif, dan sesuai dengan disiplin ilmunya yang disusun untuk memenuhi persyaratan kebulatan studi dalam program dan jenjang pendidikan yang ada di lingkungan tempat study. Skripsi disusun dengan tujuan memberi kesempatan kepada mahasiswa agar dapat memformulasikan ide, konsep, pola berpikir, dan kreativitasnya yang dikemas secara terpadu dan komprehensif, dan dapat mengkomunikasikan dalam format yang lazim digunakan di kalangan masyarakat ilmiah [3].

Pembimbing adalah dosen yang membantu mahasiswa dalam menyelesaikan tugas akhir, memeriksa konsep, kerangka dan memberikan arahan kepada mahasiswanya. Dosen pembimbing harus sesuai dengan bidang ilmu dalam judul skripsi yang diajukan mahasiswa [4]. Penguji adalah dosen yang bertugas menguji mahasiswa untuk mendeskripsikan secara jelas dan mempertanggung jawabkan skripsisebelum memperoleh gelar sarjana. Penguji akan mengajukan beberapa pertanyaan terkait dengan skripsiyang diajukan mahasiswa [4]. 


\section{ANALISIS DAN PERANCANGAN}

\section{A. Use Case Diagram}

Page | 212

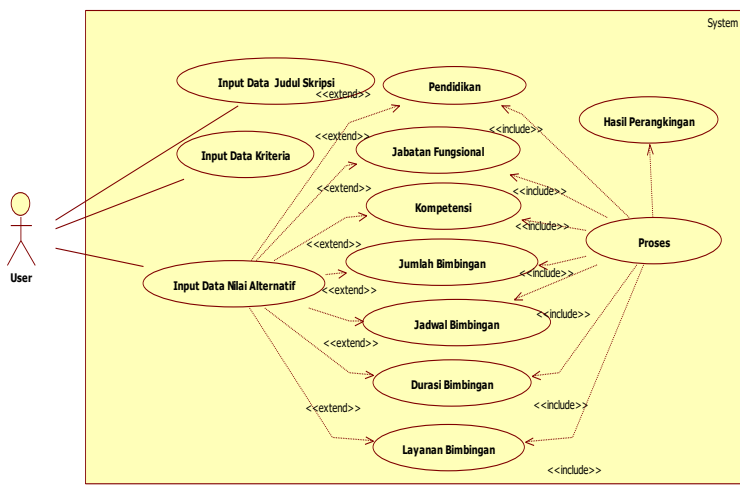

Gbr. 1 Use Case Diagram

B. Analisis Data Dengan Metode SMART

TABEL I

DATA DOSEN

\begin{tabular}{|l|l|l|}
\hline No. & NIDN & Nama Dosen \\
\hline 1 & 0123028202 & $\begin{array}{l}\text { Alexander Fernando Kawas } \\
\text { Sibero }\end{array}$ \\
\hline 2 & 0102067103 & Burhanuddin Damanik \\
\hline 3 & 0115087004 & Dini Maria Hutagalung \\
\hline 4 & 0128098102 & $\begin{array}{l}\text { Immanuel Hormat Gunawan } \\
\text { Manurung }\end{array}$ \\
\hline 5 & 0125018102 & Riah Ukur Ginting \\
\hline 6 & 0129067001 & Rianto Sitanggang \\
\hline 7 & 0107087205 & Harold Situmorang \\
\hline
\end{tabular}

TABEL II

DATA KRITERIA

\begin{tabular}{|l|l|l|}
\hline NO & Kode Kriteria & Nama Kriteria \\
\hline 1. & C1 & Pendidikan \\
\hline 2. & C2 & Jabatan Fungsional \\
\hline 3. & C3 & Kompetensi \\
\hline 4. & C4 & Jumlah Bimbingan \\
\hline 5. & C5 & Jadwal Bimbingan \\
\hline 6. & C6 & Durasi Bimbingan \\
\hline 7. & C7 & Layanan Bimbingan \\
\hline
\end{tabular}

1. Menentukan Kriteria dan Sub Kriteria

Kriteria-kriteria dan sub kriteria yang digunakan dalam penentuan dosen pembimbing dapat dilihat pada tabel III

TABEL III

KRITERIA DAN SUB KRITERIA

\begin{tabular}{|l|l|l|}
\hline NO & Nama Kriteria & Sub Kriteria \\
\hline 1. & Pendidikan & S2 \\
\hline & & S3 \\
\hline 2. & Jabatan Fungsional & Tenaga Pengajar \\
\hline & & Asisten Ahli \\
\hline
\end{tabular}

\begin{tabular}{|c|c|c|}
\hline & & Lektor \\
\hline & & Lektor Kepala \\
\hline & & Guru Besar \\
\hline \multirow[t]{4}{*}{3.} & Kompetensi & Sistem Informasi \\
\hline & & RPL \\
\hline & & $\begin{array}{l}\text { Sistem Cerdas dan } \\
\text { SPK }\end{array}$ \\
\hline & & Jaringan \\
\hline \multirow[t]{5}{*}{4.} & Jumlah Bimbingan & $0-5$ \\
\hline & & $6-10$ \\
\hline & & $11-15$ \\
\hline & & $16-20$ \\
\hline & & $21-25$ \\
\hline \multirow[t]{5}{*}{5.} & Jadwal Bimbingan & $0-3$ \\
\hline & & $4-6$ \\
\hline & & $7-9$ \\
\hline & & $10-12$ \\
\hline & & $13-15$ \\
\hline \multirow[t]{3}{*}{6.} & Durasi Bimbingan & $<=10$ menit \\
\hline & & $>10$ menit $<=20$ menit \\
\hline & & $>20$ menit $<=30$ menit \\
\hline \multirow[t]{3}{*}{7.} & Layanan Bimbingan & Online \\
\hline & & Bertemu Langsung \\
\hline & & $\begin{array}{l}\text { Online dan Bertemu } \\
\text { Langsung }\end{array}$ \\
\hline
\end{tabular}

2. Memberikan Bobot Kriteria

Pembobotan kriteria dilakukan dengan memberikan nilai antara 0-5 sesuai dengan kepentingan dari masing-masing kriteria.

TABEL IV

BOBOT KRITERIA

\begin{tabular}{|l|l|l|l|}
\hline NO & $\begin{array}{l}\text { Kode } \\
\text { Kriteria }\end{array}$ & Nama Kriteria & Bobot \\
\hline 1. & C1 & Pendidikan & 5 \\
\hline 2. & C2 & Jabatan Fungsional & 5 \\
\hline 3. & C3 & Kompetensi & 4 \\
\hline 4. & C4 & Jumlah Bimbingan & 3 \\
\hline 5. & C5 & Jadwal Bimbingan & 2 \\
\hline 6. & C6 & Durasi Bimbingan & 2 \\
\hline 7. & C7 & Layanan Bimbingan & 1 \\
\hline & & Jumlah & $\mathbf{2 2}$ \\
\hline
\end{tabular}

\section{Normalisasi Bobot Kriteria}

Bobot dari masing-masing kriteria yang sudah diproleh akan dinormalisasikan. Normalisasi dilakukan dengan membagi bobot suatu kriteria yang diperoleh dengan total bobot semua kriteria.
a. Pendidikan
$=5 / 22=0.22$
b. Jabatan Fungsional
$=5 / 22=0.22$
c. Kompetensi
$=4 / 22=0.18$
d. Jumlah Bimbingan
$=3 / 22=0.13$
e. Jadwal Bimbingan
$=2 / 22=0.09$
f. Durasi Bimbingan
$=2 / 22=0.09$
g. Layanan Bimbingan
$=1 / 22=0.04$ 
4. Memberikan Nilai Utility Untuk Setiap MasingMasing Kriteria

Dari semua kriteria yang telah ditentukan, selanjutnya dianalisa untuk menentukan nilai pengembangan utility. Nilai yang akan diberikan
TABEL V

NILAI UTILITY

\begin{tabular}{|c|c|c|c|}
\hline No & Nama Kriteria & Sub Kriteria & $\begin{array}{l}\text { Nilai } \\
\text { Utility }\end{array}$ \\
\hline \multirow[t]{2}{*}{1.} & Pendidikan & S2 & 4 \\
\hline & & S3 & 5 \\
\hline \multirow[t]{5}{*}{2.} & $\begin{array}{l}\text { Jabatan } \\
\text { Fungsional }\end{array}$ & Tenaga Pengajar & 1 \\
\hline & & Asisten Ahli & 2 \\
\hline & & Lektor & 3 \\
\hline & & Lektor Kepala & 4 \\
\hline & & Guru Besar & 5 \\
\hline \multirow[t]{4}{*}{3.} & Kompetensi & $\begin{array}{l}\text { Sistem } \\
\text { Informasi(SI) }\end{array}$ & 1 \\
\hline & & RPL & 2 \\
\hline & & $\begin{array}{l}\text { Sistem Cerdas } \\
\text { dan SPK }\end{array}$ & 3 \\
\hline & & Jaringan & 4 \\
\hline \multirow[t]{5}{*}{4.} & $\begin{array}{l}\text { Jumlah } \\
\text { Bimbingan }\end{array}$ & $0-5$ & 5 \\
\hline & & $6-10$ & 4 \\
\hline & & $11-15$ & 3 \\
\hline & & $16-20$ & 2 \\
\hline & & $21-25$ & 1 \\
\hline \multirow[t]{5}{*}{5.} & $\begin{array}{l}\text { Jadwal } \\
\text { Bimbingan }\end{array}$ & $0-3$ & 1 \\
\hline & & $4-6$ & 2 \\
\hline & & $7-9$ & 3 \\
\hline & & $10-12$ & 4 \\
\hline & & $13-15$ & 5 \\
\hline \multirow[t]{3}{*}{6.} & $\begin{array}{l}\text { Durasi } \\
\text { Bimbingan }\end{array}$ & $<=10$ menit & 1 \\
\hline & & $\begin{array}{l}>10 \text { menit }<=20 \\
\text { menit }\end{array}$ & 2 \\
\hline & & $\begin{array}{l}>20 \text { menit }<=30 \\
\text { menit }\end{array}$ & 3 \\
\hline \multirow[t]{3}{*}{7.} & $\begin{array}{l}\text { Layanan } \\
\text { Bimbingan }\end{array}$ & Online & 1 \\
\hline & & $\begin{array}{l}\text { Bertemu } \\
\text { Langsung }\end{array}$ & 2 \\
\hline & & $\begin{array}{l}\text { Online dan } \\
\text { Bertemu } \\
\text { Langsung }\end{array}$ & 3 \\
\hline
\end{tabular}

5. Hitung Bobot Nilai Utility Setiap Kriteria Masingmasing.
TABEL VI KONVERSI NILAI UTILITY

\begin{tabular}{|l|l|l|l|l|l|l|l|l|}
\hline N & Alternatif & C & C & C & C & C & C & C \\
o. & & 1 & 2 & 3 & 4 & 5 & 6 & 7 \\
\hline 1 & A1 & 4 & 1 & 2 & 4 & 1 & 2 & 2 \\
\hline 2 & A2 & 4 & 3 & 1 & 5 & 2 & 2 & 2 \\
\hline 3 & A3 & 4 & 3 & 3 & 5 & 2 & 3 & 2 \\
\hline 4 & A4 & 4 & 2 & 1 & 4 & 2 & 3 & 2 \\
\hline
\end{tabular}

Adapun proses perhitungan nilai utility penentuan dosen pembimbing seperti contoh tabel di atas dan berikut proses perhitungannya.

A1:
a. Bobot $\mathrm{C} 1=\frac{4-4}{5-4} \times 100 \%=0$
b. Bobot $\mathrm{C} 2=\frac{1-1}{5-1} \times 100 \%=0$
c. Bobot $\mathrm{C} 3=\frac{2-1}{4-1} \times 100 \%=0.33$
d. Bobot $\mathrm{C} 4=\frac{4-1}{5-1} \times 100 \%=0.75$
e. Bobot $\mathrm{C} 5=\frac{1-1}{5-1} \times 100 \%=0$
f. Bobot C6 $=\frac{2-1}{3-1} \times 100 \%=0.5$
g. $\quad$ Bobot $\mathrm{C} 7=\frac{2-1}{3-1} \times 100 \%=0.5$

A2:
a. Bobot $\mathrm{C} 1=\frac{4-4}{5-4} \times 100 \%=0$
b. Bobot $\mathrm{C} 2=\frac{3-1}{5-1} \times 100 \%=0.5$
c. Bobot $\mathrm{C} 3=\frac{1-1}{4-1} \times 100 \%=0$
d. Bobot $\mathrm{C} 4=\frac{5-1}{5-1} \times 100 \%=1$
e. Bobot C5 $=\frac{2-1}{5-1} \times 100 \%=0.25$
f. Bobot $\mathrm{C} 6=\frac{2-1}{3-1} \times 100 \%=0.5$
g. Bobot $\mathrm{C} 7=\frac{2-1}{3-1} \times 100 \%=0.5$

A3:
a. Bobot $\mathrm{C} 1=\frac{4-4}{5-4} \times 100 \%=0$
b. Bobot $\mathrm{C} 2=\frac{3-1}{5-1} \times 100 \%=0.5$
c. $\quad$ Bobot $\mathrm{C} 3=\frac{3-1}{4-1} \times 100 \%=0.66$
d. Bobot $\mathrm{C} 4=\frac{5-1}{5-1} \times 100 \%=1$
e. Bobot $\mathrm{C} 5=\frac{2-1}{5-1} \times 100 \%=0.25$
f. Bobot C6 $=\frac{3-1}{3-1} \times 100 \%=1$
g. $\quad$ Bobot $\mathrm{C} 7=\frac{2-1}{3-1} \times 100 \%=0.5$

A4:
a. Bobot $\mathrm{C} 1=\frac{4-4}{5-4} \times 100 \%=0$
b. Bobot $\mathrm{C} 2=\frac{2-1}{5-1} \times 100 \%=0.2$
c. Bobot C3 $=\frac{1-1}{4-1} \times 100 \%=0$
d. Bobot $\mathrm{C} 4=\frac{4-1}{5-1} \times 100 \%=0.75$
e. Bobot $\mathrm{C} 5=\frac{2-1}{5-1} \times 100 \%=0.25$ 

f. Bobot C6 $=\frac{3-1}{3-1} \times 100 \%=1$
g. $\quad$ Bobot $\mathrm{C} 7=\frac{2-1}{3-1} \times 100 \%=0.5$

Page | 214

TABEL VII

NORMALISASI NILAI UTILITY

\begin{tabular}{|c|l|c|c|c|c|c|c|c|}
\hline No. & Alternatif & C1 & C2 & C3 & C4 & C5 & C6 & C7 \\
\hline 1 & A1 & 0 & 0 & 0.33 & 0.75 & 0 & 0.5 & 0.5 \\
\hline 2 & A2 & 0 & 0.5 & 0 & 1 & 0.25 & 0.5 & 0.5 \\
\hline 3 & A3 & 0 & 0.5 & 0.66 & 1 & 0.25 & 1 & 0.5 \\
\hline 4 & A4 & 0 & 0.2 & 0 & 0.75 & 0.25 & 1 & 0.5 \\
\hline
\end{tabular}

\section{Hitung nilai akhir}

Nilai akhir dihitung dengan cara nilai bobot kriteria yang sudah dinormalisasi dikalikan dengan nilai utility yang sudah dinormalisasi.

$\mathrm{A} 1=(0 * 0.22)+(0 * 0.22)+(0.33 * 0.18)+$ $\left(0.75^{*} 0.13\right)+(0 * 0.09)+\left(0.5^{*} 0.09\right)+\left(0.5^{*} 0.04\right)=$ 0.221

$\mathrm{A} 2=(0 * 0.22)+(0.5 * 0.22)+(0 * 0.18)+(1 * 0.13)+$ $(0.25 * 0.09)+(0.5 * 0.09)+(0.5 * 0.04)=0.327$

$\mathrm{A} 3=(0 * 0.22)+(0.5 * 0.22)+(0.66 * 0.18)+(1 * 0.13)+$ $(0.25 * 0.09)+(1 * 0.09)+(0.5 * 0.04)=0.491$

$\mathrm{A} 4=(0 * 0.22)+(0.2 * 0.22)+(0 * 0.18)+(0.75 * 0.13)+$ $(0.25 * 0.09)+(1 * 0.09)+(0.5 * 0.04)=0.274$

\section{HASIL DAN PEMBAHASAN}

a. Form Menu Utama

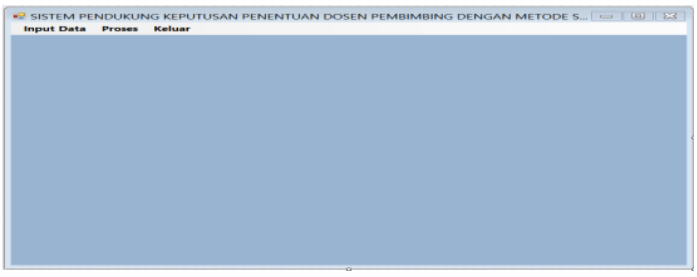

Gbr. 2 Menu Utama

b. Form Input Data Judul

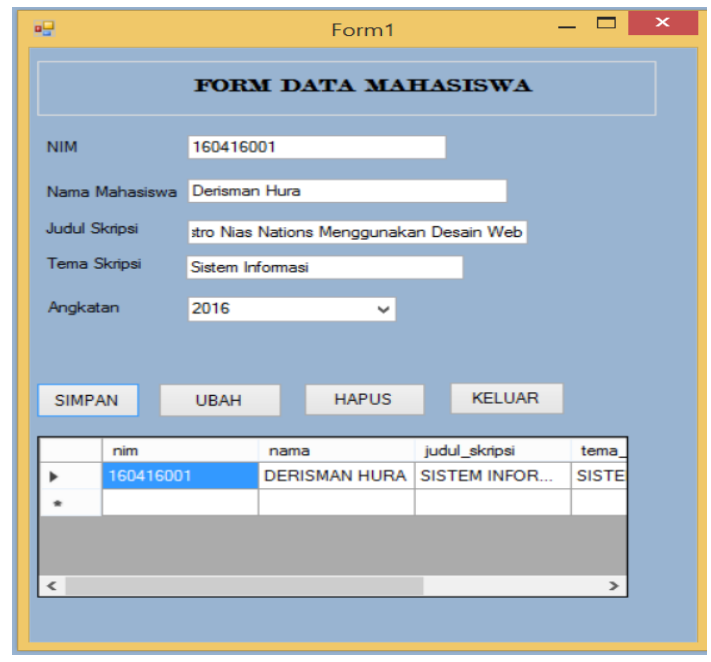

Gbr.3 Input Data Judul c. Form Input Data Kriteria

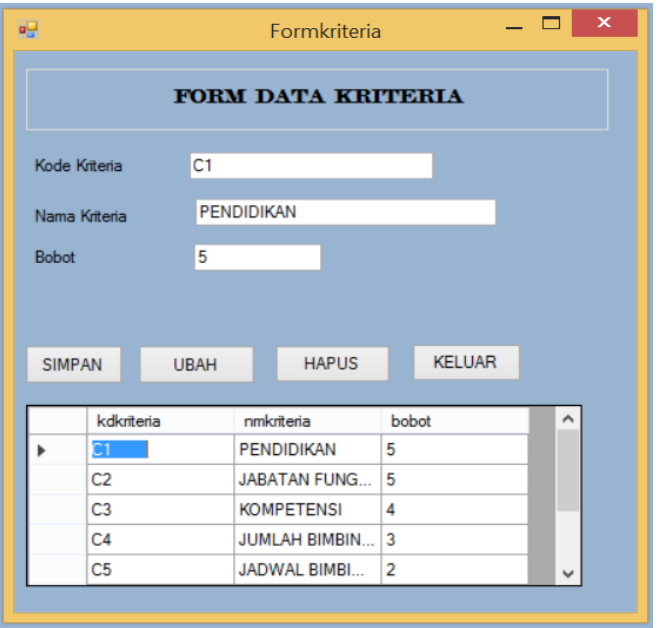

Gbr.4 Input Data Kriteria

d. Form input Nilai Utility

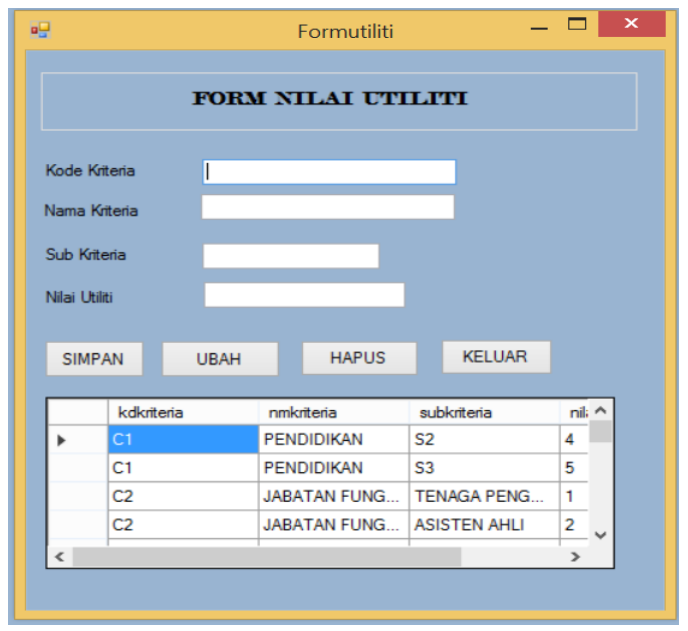

Gbr. 5Input Nilai Utility

e. Form Input Data Dosen

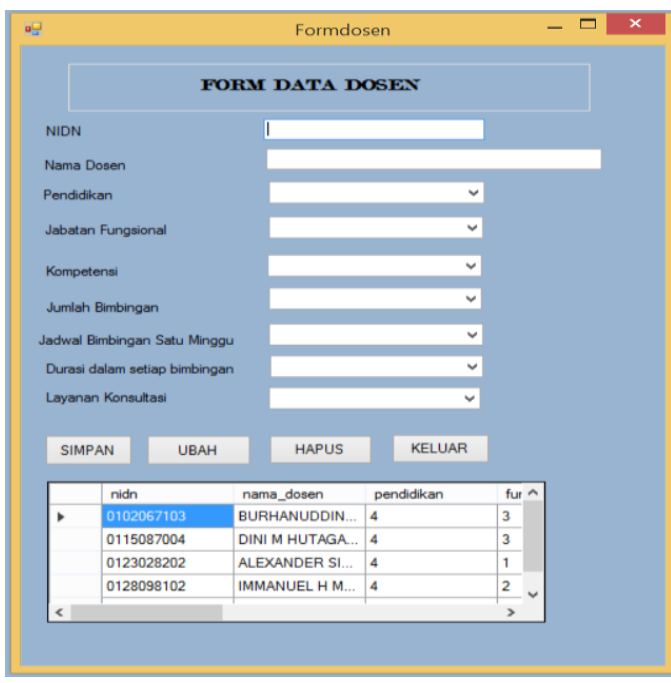

Gbr. 6 Input Data Dosen 


\section{f. Form Perhitungan Metode SMART}

Page | 215

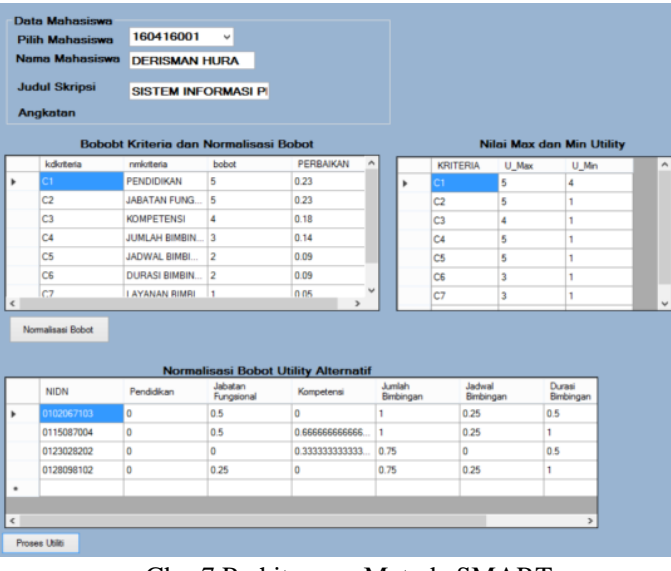

Gbr. 7 Perhitungan Metode SMART

g. Form Perhitungan Nilai Akhir

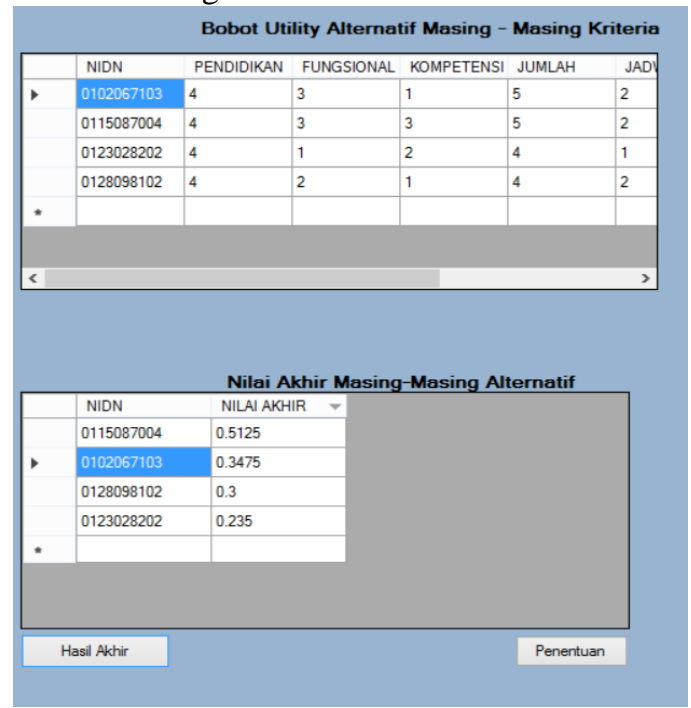

Gbr. 8 Form Nilai Akhir

h. Form Keputusan

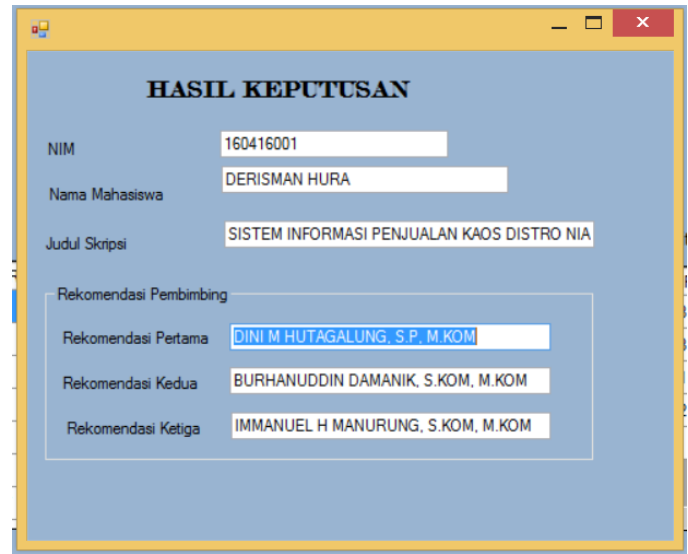

Gbr. 9 Form Keputusan

\section{PENUTUP}

Berdasarkan hasil penelitian di bab sebelumnya dapat ditarik kesimpulan sebagai berikut:

1. Dapat mengimplementasikan metode SMART pada sistem pendukung keputusan pemilihan dosen pembimbing skripsi.

2. Penghitungan sistem pendukung keputusan pemilihan dosen pembimbing skripsi telah sesuai dengan hasil perhitungan secara manual

\section{REFERENSI}

[1] Turban, E, Aronson J. E, Liang T. P, 2005, Sistem Pendukung Keputusan Dan Sistem Cerdas. Yogyakarta: Andi. Terjemahan dari Decision Support System and Intelligent Systems.

[2] Kusrini, 2007, Konsep dan Aplikasi Sistem Pendukung Keputusan. Yogyakarta: Graha Ilmu.

[3] Materi PKI Pengertian Tugas Akhir, http://staff.uny.ac.id/sites/default/files/ pendidikan/Yudant o,\%20S.Pd.\%20Jas.\%20M.Pd./MATERI\%20PKI\%20PEN GERTIAN\%20TUGAS\%20AKHIR.pdf

[4] Bab 3 Persyaratan Pembimbing, http://fsrd.isi-ska.ac.id/wpcontent/uploads/2018/06/ Bab3-Persyaratan-Pembimbing.pdf

[5] Kusumadewi, S, Hartati S, Harjoko A dan Wardoyo R, 2006, Fuzzy Multi-Attribute Decision Making (FUZZY MADM). Yogyakarta: Graha Ilmu. 